\title{
CONTATO ENTRE JORNAL E LEITOR MUDA EM FUNÇÃO DOS DISPOSITIVOS MIDIÁTICOS E DO PROCESSO DE MIDIATTIZAÇÃO
}

\author{
CONTACT BETWEEN NEWSPAPER AND READER CHANGES DUE TO \\ MEDIA DEVICES AND MEDIATIZATION PROCESS
}

\section{CONTACTO ENTRE EL DIARIO Y EL LECTOR CAMBIA EN FUNCIÓN DE LOS DISPOSITIVOS MEDIÁTICOS Y DEL PROCESO DE MEDIATIZACIÓN}

\author{
Viviane Borelli \\ Professor adjunto do Departamento de Ciências da Comunicação da UFSM \\ viviborelli10@gmail.com
}

\section{Resumo}

As práticas sociais estão mudando em função da ambiência gerada pelo processo de midiatização da sociedade. Nesse contexto, emergem outros modos de se fazer jornalismo que passa a ser cada vez mais atravessado pela tecnointeração. O objetivo do artigo é mostrar o funcionamento dos dispositivos midiáticos dos jornais gaúchos Diário de Santa Maria (DSM) e A Razão (AR) para contatar os seus leitores. Para tal, além de revisão bibliográfica foram descritos os jornais e suas mídias digitais, feitas observações nas redações e realizadas entrevistas com jornalistas, editores de seção e editores-chefe. As observações e entrevistas foram realizadas de 6 de junho a 12 de julho de 2011. Nota-se que a lógica interacional entre o jornal e os leitores muda através da oferta de um outro contrato de leitura, mas esse processo está em desenvolvimento e ocorre em distintos estágios.

Palavras-chave: Midiatização. Jornalismo. Interação. Dispositivo. Jornal.

\begin{abstract}
Social practices are changing due to the ambience generated by the process of mediatization of society. In this context, other ways of doing journalism emerge - hence its becoming more crossed by techno-interaction. This article aims at depicting the operation of media devices from two newspapers in the state of Rio Grande do Sul - Diário de Santa Maria (DSM) and A Razão (AR) - to contact their readers. For that, beyond literature review, newspapers and their digital media have been described, newsroom observations have been performed as well as journalists, subeditors and editors-in-chief have been interviewed. Observations and interviews have been performed from 6 June to 12 July 2011. We note that the interactional logic between the newspaper and its readers changes in the face of supply from another reading contract. This process is, however, developing and it occurs at distinct levels.
\end{abstract}

Key words: Mediatization. Journalism. Interaction. Device. Newspaper.

ANIMUS R. Interamericana de Comunicação Midiática, http://www.ufsm.br/revistas E-ISSN 2175-4977, v. 11, n. 21, Jan-Jun(2012) 


\section{Resumen}

Las prácticas sociales están cambiando en función del ambiente generado por el proceso de mediatización de la sociedad. En ese contexto, emergen otros modos de hacer periodismo, que pasa a ser cada vez más atravesado por la tecno-interacción. El objetivo del artículo es mostrar el funcionamiento de los dispositivos mediáticos de los periódicos Diário de Santa Maria (DSM) y A Razão (AR) para contactar a sus lectores. Para ello, además de la revisión bibliográfica, fueron descritos los periódicos y sus medios digitales, se realizaron observaciones en las redacciones y entrevistas con periodistas, editores de sección y editoresjefe. Las observaciones y entrevistas se realizaron del 02 de junio al 12 de julio de 2011. Se nota que la lógica interaccional entre el diario y los lectores cambia a través de la oferta de otro contrato de lectura, pero ese proceso está en desarrollo y ocurre en distintas etapas.

Palabras clave: Mediatización; Periodismo; Interacción. Dispositivo. Periódico.

Esta obra está licenciada sob uma Licença Creative Commons

\section{INTRODUÇÃO}

Vive-se numa sociedade em processo de midiatização que é atravessada por lógicas e protocolos midiáticos. A partir do conceito de Verón (1997) acerca do processo de midiatização das instituições compreende-se que as lógicas midiáticas afetam os campos sociais, seus sujeitos e ações. O processo de midiatização reformula a lógica do contrato, que por meio do discurso orienta um outro vínculo entre produção e recepção.

Nesse contexto, os jornais são afetados pelo imediatismo e pela lógica interacional das mídias digitais, obrigando-os a construir e a ofertar um novo contrato com seus leitores. A reflexão integra a pesquisa “A dinâmica das interações entre produção e recepção nos jornais do Rio Grande do Sul” ${ }^{1}$ e aborda especificamente as estratégias desenvolvidas pelos jornais santamarieses A Razão e Diário de Santa Maria para interagir com os leitores no contexto de uma sociedade em processo de midiatização.

Para o desenvolvimento da pesquisa vão ser estudados também os jornais O Pioneiro (Caxias do Sul, RS), A Gazeta do Sul (Santa Cruz, RS), O Nacional (Passo Fundo, RS), e A Plateia (Sant’Ana do Livramento). Estão previstas distintas fases que abrangem pesquisa nas organizações jornalísticas, suas hierarquias e cultura organizacional; identificação dos

\footnotetext{
${ }^{1}$ Com apoio financeiro do Governo do Estado do Rio Grande do Sul por meio da Fapergs (PqG 2011/2013). Uma versão anterior do artigo foi apresentada na mesa coordenada “Jornalismo midiatizado" no $9^{\circ}$ Encontro Nacional de Pesquisadores em Jornalismo (SBPJor 2011).
} 
protocolos interacionais entre recepção e produção através de análise dos dispositivos midiáticos dos jornais (jornal impresso e mídias digitais), observação das rotinas de produção e dos dispositivos interacionais engendrados na e pela produção. Através da seleção de um corpus representativo de edições, serão analisados os contratos de leitura dos jornais para compreender que estratégias utilizam ao buscar vínculo com os leitores. Após essas etapas, vão ser selecionados enunciados postados por leitores nos dispositivos midiáticos digitais para compreender as motivações e os modos através dos quais os leitores contatam o "seu jornal”.

Após mapeamento do organograma das redações e suas respectivas hierarquias, foram definidos os entrevistados de acordo com a função que exerciam ${ }^{2}$. A intenção foi ouvir os editores-chefe, repórteres e de editores de seção. As entrevistas semi-estruturadas (GIL, 2006) foram realizadas de acordo com a disponibilidade dos entrevistados, segundo um pré-roteiro de questões sobre os mecanismos de interação com o leitor e o estágio atual do jornalismo impresso e da prática jornalística.

Para os editores questionou-se especialmente sobre as estratégias de contato com os leitores, em que medida o leitor pode ser considerado um co-produtor, que uso fazem dos dispositivos digitais, como é a relação entre a Redação e os demais setores do jornal, qual é a função do conselho editorial ou de leitores. Para os repórteres e editores de seção, as perguntas centraram-se nas ferramentas utilizadas para manter contato com os leitores, se e como a interação com os leitores influencia na rotina jornalística, como lidam com a multifunção e a necessidade de produção de conteúdo para diferentes dispositivos. O préroteiro foi adaptado a cada jornal devido às diferentes hierarquias e modos de organização da Redação e também foi adequado a cada entrevistado de acordo com sua função específica.

Os conceitos de midiatização, interação, leitor e dispositivo são discutidos inicialmente para compreender o processo de midiatização do jornalismo e as lógicas interacionais propostas na e pela produção. Por fim, os dados obtidos no trabalho de campo são problematizados diante dos conceitos abordados anteriormente para que se possa compreender o processo de midiatização do jornalismo e o funcionamento dos dispositivos de interação implantados pela instância da produção.

\footnotetext{
${ }^{2}$ Para o trabalho de campo, contou-se com a colaboração da aluna Francieli Jordão Fantoni. Participam do projeto os alunos Rogério Saldanha Correa (bolsista FIPE Junior) e Débora Dalla Pozza (participante) e a professora Elisangela Carlosso Machado Mortari.
} 


\section{JORNALISMO EM PROCESSO DE MIDIATIZAÇÃO}

O jornalismo trabalha com um leitor ideal ou imaginário (ECO, 1979) aquele projetado pela equipe do jornal - e com um leitor real - o que efetivamente lê o jornal e produz seus próprios sentidos. Se essa relação era outrora hipoteticamente distante hoje é cada vez mais tensionada em função do processo de midiatização da sociedade, que afeta os campos, os sujeitos e a própria mídia.

O processo de midiatização da sociedade ao longo do século passado, de acordo com Boutaud e Verón (2007), tem mostrado que as práticas sociais são complexas e que as relações não são homogêneas. Pelo contrário, para os autores, a interface entre a produção e a recepção representa o "vínculo de engendramento de uma crescente complexidade das sociedades”33 (BOUTAUD e VERÓN, 2007, p.3).

A mídia se converteu em um objeto instigante de estudos sobre a transformação das práticas sociais. Há uma série de estudos que tomam o conceito de midiatização para compreender as práticas dos campos sociais (política, esporte, religião, ciência, jornalismo) e de seus sujeitos na sociedade midiatizada ${ }^{4}$.

A midiatização se constitui num complexo processo em que os dispositivos midiáticos agem sobre outros campos sociais, estruturando e engendrando suas ações por meio de operações técnicas e simbólicas. O jornalismo é considerado uma prática específica que faz parte de um campo mais amplo, o midiático que tem a função de visibilizar as ações dos outros campos e legitimá-las (RODRIGUES, 2000).

Há uma nova lógica produtiva que ultrapassa a constatação de que a mídia cumpre apenas um papel de mediação entre os campos sociais, visibilizando-os e legitimando seus discursos. Acredita-se que como os campos e seus sujeitos fazem adequações ou mudam seus modos tradicionais de agir em função de lógicas midiáticas temos afetações por parte das mídias, suas estruturas, processos e culturas.

\footnotetext{
${ }^{3}$ Tradução própria.

${ }^{4}$ Sobre as relações do campo midiático e jornalístico: SOSTER, 2007; FAUSTO NETO (2006) Sobre as relações entre os campos religioso e midiático: BORELLI, Viviane (org.). Mídia e religião: Entre o mundo da fé e o do fiel. Rio de Janeiro, RJ: E-Papers, 2010. Sobre mídia e política ver FAUSTO NETO, A; RUBIM, A.A. Canelas; VERÓN, E. Lula Presidente: televisão e política na campanha eleitoral. São Paulo: Hacker; São Leopoldo, RS: Unisinos, 2003.
} 
Para Fausto Neto (2007) vivemos uma nova cultura, a midiática, que estabelece novos protocolos de linguagens e redimensiona as práticas sociais. A sociedade funciona e se constitui, hoje, através de uma cultura midiática, que serve de referência para a organização social, especialmente, através de suas lógicas e operações. O autor refere que a convergência de aspectos "sócio-tecnológicos, disseminados na sociedade segundo lógicas de ofertas e de usos sociais produziu, sobretudo nas três últimas décadas, profundas e complexas alterações na constituição societária, nas suas formas de vida, e suas interações” (FAUSTO NETO, 2007, p. 92).

Essas novas modalidades de produção de sentidos geradas pela midiatização representam um outro modo de vida. A midiatização é mais que uma mediação singular e representa "um novo modo de ser no mundo" (GOMES, 2006, p. 113), pois se está numa nova ambiência. A midiatização é um processo complexo que se institui como uma outra maneira de vida, um novo ambiente que tem ressonâncias sobre a constituição humana.

A cultura midiática impõe novas formas de vivência e práticas por parte dos campos sociais. A interação que outrora ocorria de forma presencial e direta hoje depende de dispositivos midiáticos, o que caracteriza uma sociedade em processo de midiatização na medida em que as instituições nos termos de Verón (1997) ou os campos (RODRIGUES, 2000) estão articulados à mídia e às suas lógicas de funcionamento.

As mediações tradicionais dão lugar às tecnointerações, já que as interações dependem dos “dispositivos de mídia (internet, rádio, televisão, etc.), portanto, é visceramente atravessada pelo fenômeno da midiatização” (SODRÉ, 2009, p.2). São os dispositivos midiáticos que garantem as interações entre sujeitos e campos.

A articulação entre novas tecnologias, formações culturais e dispositivos midiáticos representam o surgimento de uma nova matriz para a "produção simbólica dotada de um estatuto próprio e complexo que tanto funde modos de interações anteriores com novas formas expressivas” (MATA, 1999, p.83), o que denota mudanças nas práticas sociais.

\section{JORNAL E DISPOSITIVOS DE INTERAÇÃO}


Sabe-se que o jornal deve manter-se vivo e em contato com seus leitores como estratégia de sobrevivência diante da oferta de outros dispositivos midiáticos. Para tal, a marca do jornal precisa ser enunciada e valorizada, pois no sentido abordado por Landowski (1992), o jornal é um sujeito semiótico que precisa buscar vínculos com seus leitores de tal forma que eles sintam a necessidade de contatá-lo todos os dias.

Em função desse vínculo e do reconhecimento por parte de seus leitores, o jornal não pode mudar de forma radical e as modificações que faz devem ser graduais. Rebelo (2000, p.41) conclui que "qualquer jornal é extremamente prudente quanto pretende mudar de formato, alterar a disposição das rubricas, introduzir ilustrações, usar a cor”. Esses cuidados são tomados para que os hábitos não sejam rompidos e o leitor continue identificando as marcas de "seu jornal”.

Na relação entre jornal e leitor é preciso haver algo que seja comum aos dois. Na visão de Rebelo (2000, p.44) “para que haja efectiva relação jornal/leitor, concretizável no acto de compra, é necessário, contudo, que a imagem do leitor junto do jornal e que a imagem do jornal junto do leitor apresentem uma zona comum. Quanto maior for essa zona comum mais de reforça a relação de fidelização leitor/jornal”. O vínculo, portanto, só se concretiza nessa dupla relação: o leitor se apropria do jornal para lê-lo e o jornal toma a sua atenção.

Nas palavras de Eliseo Verón, em prefácio à obra de Mario Carlón ${ }^{5}$, nas relações entre produção e recepção há "zonas de interpenetração” que entram no processo interativo para além do sistema. Mesmo que o sistema possua algumas especificidades e lógicas próprias de funcionamento, a ambiência da midiatização provoca alguns processos colaterais que ocorrem “entre” e que não estão fixados e demarcados de antemão em uma ou outra instância. Ou seja, apesar de os contratos propostos pela produção pressuporem algumas prescrições é nas lógicas do contato que se efetivam ou não. Dessa forma, os fatores decisórios estão subjugados às relações processuais e à complexidade do fenômeno da midiatização.

O contrato de leitura é o responsável pelas relações entre produção e recepção. Como concebe Boutaud e Verón (2007, p.4), “a noção de contrato é aqui uma metáfora que designa este vínculo, que se justifica na medida em que a estabilidade dessa relação implica a

\footnotetext{
${ }^{5}$ CARLÓN, Mario. Sobre lo televisivo: dispositivos, discursos y sujetos. Buenos Aires: La Crujia, 2004.
} 
dimensão da confiança no tempo, e as expectativas que concernem às características do produto discursivo em questão"6.

Os contratos de leitura são construídos através de operações discursivas e é por meio deles que as mídias contatam seus públicos leitores. Compreende-se que há um dispositivo técnico e simbólico que tem a função de dar forma aos contratos produzidos no âmbito da produção com objetivo de atingir a recepção. O conceito de dispositivo midiático é central para compreender a problemática visto que é ele que garante múltiplas interações entre produção e recepção via contratos de leitura.

Verón (1997, p.13) conceitua que a mídia como um "meio de comunicação social é um dispositivo tecnológico de produção-reprodução de mensagens associado a determinadas modalidades (ou práticas) de recepção de mensagens ditas”. Esse dispositivo engendra complexos processos de produção de sentidos a partir da circulação de mensagens, onde levase em conta a instância da recepção.

Mouillaud (1997) afirma que o dispositivo deve ser pensado como uma matriz, em que ele “não comanda apenas a ordem dos enunciados, mas a própria postura do leitor” (p.32). O conceito está vinculado diretamente ao funcionamento do jornalismo e explicita a idéia de que o dispositivo não é só o suporte técnico onde os discursos são enunciados, mas também uma matriz que orienta e que co-determina os vínculos que os leitores estabelecem com essa oferta discursiva.

O dispositivo pode ser também entendido como um lugar de inscrição do texto que "tem uma forma que é sua especificidade, em particular, um modo de estruturação do espaço e do tempo” (MOUILLAUD, 1997, p.35) assinala o autor. Essa maneira de estruturar está ligada à sua própria composição, que se relaciona com demais mecanismos. Por exemplo, o jornal está inscrito no dispositivo geral da informação, contendo outros elementos que lhe devem subordinação, como o sistema de titulação. Dessa forma, cada uma das seções dos jornal e suas partes constituintes são compreendidas como dispositivos que integram o dispositivo midiático mais amplo, o jornal. O dispositivo midiático é constituído, portanto, por agenciamentos e mecanismos técnicos e simbólicos tanto em nível micro quanto macro estrutural.

\footnotetext{
${ }^{6}$ Tradução própria.
} 
O conceito de dispositivo está também atrelado à compreensão da produção de sentidos "não mais a partir do suporte tecnologia ou linguagem, mas de um conjunto de relações práticas, discursivas e tecnológicas” (FERREIRA, 2003, p.91). O dispositivo é mais que um suporte tecnológico que liga dois sujeitos e também não está reduzido à função linguística, já que abrange um emaranhado de relações de ordem técnica e simbólica. Nos termos do autor, o dispositivo envolve elementos técnicos, normativos e discursos, constituindo-se a partir do agrupamento de distintos objetos.

Compreende-se que o trabalho do dispositivo acaba gerando novas modalidades de contato e de interação, em que as normas e os modos de operar anteriores são revistos e reformulados a partir de outras operações de sentidos. Isso sugere pensar que o funcionamento do próprio dispositivo jornal possibilita alterações em suas regras, atualizações dos vínculos e dos processos de produção de sentidos por parte dos agentes de mídia.

Uma outra lógica interacional opera na cultura da convergência, que engloba mudanças no âmbito da produção e no consumo das mídias. Como pressupõe Jenkins (2009, p. 41-42), as mídias tradicionais não são substituídas, mas "suas funções e status estão sendo transformados pela introdução de novas tecnologias”.

O autor concebe a convergência midiática não só como uma mudança tecnológica, pois ela transforma as relações entre "tecnologias existentes, indústrias, mercados, gêneros e públicos. A convergência altera a lógica pela qual a indústria midiática opera e pela qual os consumidores processam a notícia e o entretenimento (2009, p. 43). Ou seja, a instância da recepção utiliza tecnologias e contata distintas mídias para ter mais acesso e controle sobre os fluxos de informação, buscando a interação não só com os dispositivos midiáticos, mas também com outros sujeitos (leitores, telespectadores, ouvintes e internautas).

É nesse sentido que para compreender a midiatização do jornalismo e os modos através dos quais esse fenômeno afeta o processo interacional entre produção e recepção é que a pesquisa se propõe a analisar as processualidades (as organizações jornalísticas, as rotinas produtivas, os dispositivos midiáticos e os leitores/consumidores).

Entende-se que a sociedade em processo de midiatização cria novas mídias e institui outras formas de interação. Nesse sentido, o jornal fica atrás das mídias digitais no que tange a conceitos caros ao jornalismo como de atualidade e imediatismo. Diante de nova ameaça de 
perda de leitores, as mídias impressas passaram a desenvolver estratégias para continuar presentes no cotidiano e atrair leitores. A segmentação editorial, o diálogo com outras mídias, a chamada de atenção para si, a complementação e o aprofundamento de conteúdos já abordados por outras mídias são algumas dessas estratégias.

A mídia impressa passa por mudanças no seu processo de produção jornalística e no modo de apresentação do produto visando a criação de estratégias de interação com os leitores para buscar a manutenção e a ampliação do contato com seus públicos. Para Antonio Fausto Neto a enunciação jornalística sofre mutações e não aponta mais a realidade construída, pois passa a descrever e detalhar o processo de construção da notícia para buscar novos vínculos com seus receptores e estabelecer padrões de credibilidade. Ou seja, o jornalismo não só mostra os fatos da atualidade, mas, sobretudo, detalha os processos através dos quais constrói a realidade, que o autor destaca como sendo a "realidade da construção” (FAUSTO NETO, 2006, p.1).

Nesse contexto de produção autorreferencial, estaríamos vivendo a fase de um jornalismo midiatizado em que, para Soster (2007), a prática jornalística é calcada não só num processo autorreferencial, mas também correferencial na medida em que o conteúdo de uma mídia é utilizado por outra como fonte. Ocorrem diálogos entre as distintas mídias, de tal forma que no próprio sistema midiático circulam informações sobre o dispositivo e também entre mídias distintas.

Exemplo desse processo é a constante enunciação que o DSM faz de mídias digitais, buscando instigar o leitor a ter mais informações e acessar conteúdo complementar em outros dispositivos da mesma organização. Nota-se que os dispositivos midiáticos funcionam de forma interligada, em que um alimenta ao outro em termos não só de conteúdo, mas também de referência.

A seguir, vão ser apresentados e discutidos os dados de campo tendo como eixo central a problemática dos dispositivos interacionais implantados na e pela produção como estratégia de contato com a instância da recepção. Inicia-se com a descrição dos dispositivos jornal e mídias digitais - para depois problematizar as falas dos jornalistas do Diário de Santa Maria e de A Razão diante dos conceitos abordados. 


\section{AS ESTRATÉGIAS DE ‘CONTATO’ COM OS LEITORES}

O Diário de Santa Maria (DSM) pertence à Rede Brasil Sul (RBS) de Comunicação e foi criado em $2002^{7}$. O jornal tem, em média, 16 páginas, em cor. O nome das editorias é em caixa alta e há fotos dos editores e contato (telefone e e-mail). No final de semana há ainda o caderno Mix (variedades) e Classificados. Em relação aos dispositivos criados pela produção para contatar a recepção há na capa, abaixo do nome do jornal, o endereço eletrônico (www.diariosm.br). Na coluna da esquerda sempre há referência a algum blog.

No canto superior esquerdo da página 2 aparece novamente a referência ao website e o leitor é convidado a participar de enquete. No final da página aparece há o enunciado: “siga o Diário de Santa Maria no twitter: twitter.com.br/diariosm”. No centro da página há uma pergunta/dúvida enviada por leitor (cita-se o nome) e a resposta. Há o endereço ou email para esse contato. Ao lado desta chamada tem outro ‘selo' no qual o leitor pode enviar “dsm” pelo celular e receber as duas principais notícias do jornal.

Na seção Cidade da página 3 há o endereço do website, ao lado da matéria "Frio de congelar”, com o enunciado: “confira uma galeria de fotos de frio”. Diante da impossibilidade de mais espaço e de maior interação com o leitor, o jornal cria estratégias para sanar esses problemas, criando outras estratégias para prolongamento desse contato com o leitor.

Na página 4, de Opinião, é publicado um artigo enviado por leitores, além da carta do leitor, que pode ser enviada por carta ou email. O mesmo ocorre na editoria de Social, em que há uma galeria de fotos do leitor. “A gente recebe muitas pautas e fotos do leitor (....). A nossa

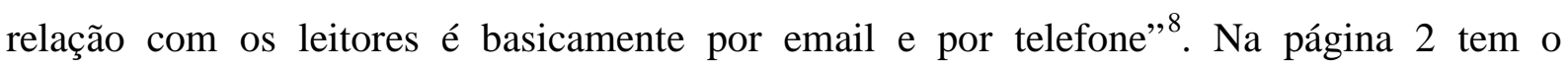
expediente do grupo RBS e referências ao DSM, o nome da editora chefe, do gerente comercial e o website. Na página 15 aparece o expediente, os respectivos contatos (email e telefone) dos responsáveis pelas editorias. Na contracapa, há ainda o “Fale com o Diário”, com endereço e telefone da RBS SM, o contato para assinaturas e anúncios.

Em todas as editorias (Economia, Política, Geral, Esportes, Polícia), aparece no canto superior o nome da seção, do editor, sua foto (uma forma de protagonização do jornalismo e referência a si mesmo, como aponta FAUSTO NETO, 2006), o telefone e o email. São possibilidades de o leitor entrar em contato diretamente com quem é responsável pela editoria

\footnotetext{
${ }^{7}$ Em 19 de junho de 2012, o jornal passou a circular com novo projeto gráfico. Para esse artigo, toma-se como referência a edição de 6 de junho de 2011, segunda-feira, ano 9, número 2.791.

${ }^{8}$ Da repórter do DSM Silvia Medeiros, em entrevista concedida no dia 20 de junho de 2011, na sede do jornal.
} 
para ter a oportunidade de participar, sugerir, questionar. As matérias assinadas trazem no início o nome do repórter ao final o email. Deixar visível na edição impressa as formas de contato através de outros dispositivos mais imediatos é uma estratégia da produção para mostrar que está ofertando possibilidades interacionais que vão além da publicação diária. É sobre esses mecanismos que o jornal institui seu contrato de leitura.

O DSM faz referências às outras mídias do Grupo RBS como forma de divulgação da sua 'marca', de ampliação do contato com o leitor para continuar 'vivo' em sua memória e como estratégia de sobrevivência, pois é preciso unir-se a outros dispositivos que permitem mais instantaneidade e interatividade. Compreende-se que o processo de midiatização do jornalismo faz com que o DSM se autorrefira e enuncie as outras mídias numa cadeia contínua de proliferação de conteúdo e de enunciação de sua 'marca'.

Uma estratégia é referir na versão impressa os blogs: Perfil Empreendedor, Vestibulog, Ao Vivo!, Blog do Meio Ambiente, Diário de Fotógrafo, Atlântida Santa Maria, Grings, Livro de Receitas do Diário, Meu Filho, Aparte, A Varejo, Da arquibancada, Zoom, Bastidores do Diário e Viva a Faixa. A maioria está vinculado a editorias do jornal impresso, a colunas ou a campanhas específicas (Viva a Faixa) e as atualizações variam de acordo com os temas abordados (Vestibulog, restrito a coberturas mais amplas durante os vestibulares e q publica informações variadas durante todo o ano).

Além de referir os blogs, o jornal menciona a televisão e as emissoras de rádio. Os colunistas fixos têm seus nomes e emails publicados junto a uma chamada: "estará no programa Wake-up da Itapema” ${ }^{9}$. O DSM propõe um novo contrato de leitura em que instiga o seu leitor a não só consumir o dispositivo impresso, mas também outros. O leitor é convidado a estar em contato com todas as mídias do grupo.

“O jornalismo impresso está sofrendo o impacto da concorrência com o online e está tentando se posicionar em relação ao online” ${ }^{10}$. Para o editor de On Line, o jornal procura ofertar mecanismos de interação, mas o leitor do jornal ainda não está habituado a participar das possibilidades interacionais propostas pelo DSM. “O leitor do Diário de Santa Maria participa pouco. Se eu coloco uma enquete na capa, eu noto que é muito pouca a participação das pessoas"11.

\footnotetext{
${ }^{9}$ A partir de 2 de julho de 2012, a Itapema Santa Maria sairá do ar para entrada da Gaúcha, também do Grupo RBS na frequência 107,5 FM (DSM, 15/06/2012).

${ }^{10}$ Do editor de On Line do DSM Paulo Chagas, em entrevista concedida no dia 21 de junho de 2011, na sede do jornal.

${ }^{11}$ Idem.
}

ANIMUS R. Interamericana de Comunicação Midiática, http://www.ufsm.br/revistas E-ISSN 2175-4977, v. 11, n. 21, Jan-Jun(2012) 
Nota-se que o jornal oferta possibilidades de contato que não possuem resposta do leitor, o que denota que o dispositivo não conhece suficientemente as demandas e anseios de seus públicos e que não está preparado para enfrentar a complexidade interacional da sociedade em processo de midiatização.

O website é dividido em três colunas. A esquerda é de acesso rápido ao conteúdo das editorias (capa, blogs, plantão, galerias de fotos, vídeos e RSS) e funções do jornal. A do centro é dedicada à postagem de matérias, vídeos e destaques. O da direita é destinado às publicidades.

Em Interatividade, os leitores podem interagir através de enquete, mural, promoções, twitter e facebook (que passou a ser utilizado pelo jornal no final de 2011). As notícias podem ser comentadas e para tal, há a visualização de um “Termo RBS” que detalha as condições para publicação de comentários. O dispositivo permite a interação sob certas lógicas e regras. Por exemplo, no blog do Grings, há: “Notificar-me dos próximos comentários via e-mail; Eu aceito os termos e condições de Grings (obrigatório)”"12. O twitter é utilizado para postar matérias e eventos.

O Diário foi criado numa sociedade em processo de midiatização, com múltiplas possibilidades interacionais. “O Diário já nasceu com essa qualidade positiva que é de um leitor entrar em contato com o jornal, pedir pautas, sugerir assuntos, abordagens, criticar. Essa coisa dos celulares baterem fotos também é importante”13.

As tecnologias de comunicação são apontadas pelo DSM como propulsoras para a participação dos leitores seja via e-mail, website ou telefone. Mas, para os editores e repórteres do jornal A Razão, o telefone e o contato direto durante uma pauta na rua assim são os mecanismos centrais para a relação com o leitor.

O Jornal A Razão ${ }^{14}$ circula em Santa Maria e região desde 1934, faz parte da Empresa Jornalística De Grandi, numa média de 16 páginas. São cor cerca de 8 páginas: capa e contracapa, de 2 a 4 internas, cadernos e sociais. As editorias são: Página 2, Política, Opinião, Geral, Segundo A Razão (variedades), Sociais, Economia, Serviços, Esportes,

\footnotetext{
${ }^{12}$ As referências as mídias digitais do Grupo RBS e seus dispositivos são relativas a observações realizadas durante os meses de junho e julho de 2011.

${ }^{13}$ Da editora-chefe do DSM, Andreia Fontana, em entrevista concedida no dia 20 de junho de 2011, na sede do jornal.

${ }^{14}$ Toma-se como referência a edição de 6 de junho de 2011, segunda-feira, ano 77, número 206.
} 
Polícia e Agenda. Durante a semana circulam ainda os cadernos: Teen, Veículos, A Razão de Ler, Classificados (4 ${ }^{\text {a }}$ feira e sábado/domingo).

Na Página 2 é disponibilizado espaço para o leitor emitir suas opiniões por meio de cartas ou e-mail (editoria@arazao.com.br). Na página 4 há o expediente com os nomes do editor e subeditor e dois emails de contato (Redação e Comercial), além do endereço do website, telefones e do endereço.

O protagonismo observado em relação aos jornalistas do DSM não ocorre em AR. Outro diferencial é que grande parte das matérias não são assinadas e não há e-mail de contato do repórter, nem telefone ou e-mail dos responsáveis. A exceção é o caderno Segundo A Razão que traz na seção Sociais o email social@arazao.com.br junto a foto da colunista, além de ter espaço na seção Variedades para carta de leitores.

Na capa, sempre aparece o endereço do website: www.arazao.com.br onde está hospedada a edição impressa na íntegra. Nas páginas internas (exceto no Expediente, página 4) não há referência ao website e o jornal não possui blogs, twitter ou facebook. No website ${ }^{15}$, os leitores podem comentar qualquer matéria desde que se identifiquem com nome completo e email e preencham um retângulo anti spam. Pode-se interagir por email (geral, Redação, Comercial, Circulação e Recursos Humanos). No link Contatos são disponibilizados o número de telefone da Redação, Comercial e Circulação. O telefone é o principal mecanismo de contato com o leitor. "É esse que toca toda hora, chama-se telefone. (...) A gente vai numa comunidade com o carro escrito A Razão, daí eles vem conversar com a gente. Isso é uma forma de interação importante»"16.

Os dispositivos técnicos e simbólicos transformam a lógica do contato tradicional mas não a excluem. Para os editores, o contato com o leitor deve ocorrer no dia a dia: “o leitor está sempre mantendo contato com a gente, seja na rua, quando veem um repórter ou quando ligam” ${ }^{17}$. Para a sub-editora de AR, o jornal torna-se imprescindível porque a internet ainda não atinge todos os leitores.

Os jornalistas que atuam em AR ainda avaliam o crescente desenvolvimento de tecnologias e a convergência de culturas como algo incerto e novo. "Isso é um fenômeno

\footnotetext{
${ }^{15} \mathrm{O}$ website do jornal foi reformulado no primeiro semestre de 2012, com criação de blogs como "Verde que te quero verde” (AR, 13/06/2012).

${ }^{16}$ Da repórter de AR, Luisa Canaã, em entrevista concedida no dia 6 de junho de 2011, na sede do jornal.

${ }^{17}$ Da sub-editora de AR, Clodilde Gama, em entrevista concedida no dia 12 de julho de 2011, na sede do jornal.
} 
novo e a gente tem muito o que aprender ainda. Mesmo os grupos de comunicação que estão mais avançados nesta área de interação entre todas as tecnologias ainda não conseguiram compreender a dimensão desse fenômeno" ${ }^{18}$. O editor problematiza a complexidade do fenômeno de midiatização da sociedade e a afetação da prática jornalística em função dos múltiplos dispositivos midiáticos que possibilitam interação com o leitor, salientando que ainda não há como compreender e dominar esses novos protocolos.

A midiatização das práticas sociais está em curso e tem afetado o modo de se fazer jornalismo. É preciso conhecer as demandas dos leitores e suas expectativas. Para isso, o contato deve ser ampliado e efetivado. Se outrora não se conhecia o leitor, agora é preciso compreender e satisfazer seus anseios, sob risco de perde-lo.

\section{CONSIDERAÇÕES}

Ao contrário do DSM que desenvolve estratégias para ampliar o contato com seus leitores numa sociedade afetada pelo processo de midiatização, o jornal A Razão permanece preocupado e centrado na versão impressa. Essa diferença se explica em parte pela história de cada um: AR possui mais de 70 anos e faz parte de uma empresa familiar enquanto o DSM integra o maior grupo de comunicação da região Sul do Brasil e nasce no século XXI.

O jornal A Razão ainda oferta as formas de contato tradicionais, parecendo estar à margem da sociedade em processo de midiatização. Não há como compreender o fenômeno em sua complexidade porque o jornal foi criado e se expandiu numa época anterior ao desenvolvimento e à aceleração da convergência midiática. AR era o único diário em Santa Maria até a entrada do concorrente em 2002, tendo de se reestruturar e criar novas estratégias de permanência no mercado editorial de jornais.

Nesse sentido, como conceitua Landowski (1992) acerca da identidade do jornal, é preciso mudar aos poucos. Nos últimos 10 anos, A Razão introduziu outras possibilidades de contato com o leitor por meio de mais e-mails (por seções e não só apenas o geral da Redação), depois reformulou seu projeto gráfico, aumentou o número de páginas coloridas e finalmente em 2012 oferta uma nova página na web com atualizações mais frequentes.

O DSM já nasce numa cultura midiática e numa sociedade em processo de midiatização que desafia as grandes corporações jornalísticas a buscarem novos modos de

\footnotetext{
${ }^{18}$ Do editor de AR, José Mauro Batista, em entrevista concedida nos dias 6 e 13 de junho de 2011, na sede do jornal.
} 
contato com seus públicos. A partir da virada do século, a RBS expandiu de forma acelerada seus jornais, passando de quatro para oito: adquiriu A Notícia (SC, em 2006) e criou três - o Diário de Santa Maria (2002) e os direcionados para o segmento mais popular: Diário Gaúcho (2000) e Hora de Santa Catarina (2006). A segmentação editorial é uma tendência do jornalismo impresso para enfrentar a concorrência das outras mídias, pois é preciso atingir todos os públicos.

Nesse contexto, o desafio dos jornais é questionar-se sobre seu diferencial em relação à ampla gama de conteúdo ofertada pela segmentação da televisão e pelas distintas mídias digitais. A segmentação editorial é uma alternativa, assim como o diálogo com outros dispositivos para enunciação de seus conteúdos e de suas práticas em múltiplos processos de referenciação.

Os dois jornais buscam a interação com os seus leitores por meio de mecanismos preestabelecidos como a carta do leitor, o e-mail, o telefone, o website ou, no caso do DSM, ainda o convite para postar um comentário no blog, enviar foto, pergunta sugestão ou o seguir no twitter. Há especificidades no sistema produtivo de cada um, pois o DSM possibilita mais interações, mas as controla e impõe regras para tal.

A pesquisa dá algumas pistas de como a instância da produção concebe o leitor. No caso do Diário, os leitores são instigados a contatarem o "seu jornal” por meio de um novo contrato de leitura que prevê a possibilidade interacional através de distintos dispositivos. Mas, percebe-se que há uma matriz geradora de sentidos que propõe um contato com seu leitor, mas ela o faz a partir de alguns regramentos e de lógicas próprias. Já AR vê o momento atual como incerto, o que é utilizado como pretexto para não serem desenvolvidas novas estratégias de contato com seus leitores.

\section{REFERÊNCIAS}

A Razão, ano 77, número 206, de 6 de junho de 2011.

BOUTAUD, Jean-Jacques e VERÓN, Eliseo. Del sujeto a los actores. La semiótica abierta lãs interfaces. In: Sémiotique ouverte. Itinéraires sémiotiques en communication. Paris: Lavoisier, Hermes Science, 2007. Texto avulso.

ECO, Umberto. Leitura do texto literário: lector in fabula. Lisboa: Presença, 1979. 
FAUSTO NETO, Antonio. Mutações nos discursos jornalísticos: 'da construção da realidade’ a 'realidade da construção'. Congresso Brasileiro de Ciências da Comunicação Intercom, $2006 . \quad$ Disponível em: http://www.intercom.org.br/papers/nacionais/2006/resumos/R1804-1.pdf . Acesso em 25 de julho de 2009.

Fragmentos de uma ‘analítica' da midiatização”. Revista Matrizes. São Paulo: ECA/USP, ano 1, $\mathrm{n}^{\mathrm{o}}$ 1, 2007, pp. 89-105. Disponível em: http://www.usp.br/matrizes/img/02/Dossie5_fau.pdf. Acesso em: 13/07/2008, 2007.

Diário de Santa Maria, ano 9, número 2.791 de 6 de junho de 2011.

FERREIRA, Jairo. O Conceito de Dispositivo: explorando dimensões de análise. In: Ecos revista. Revista da Escola de Comunicação Social V.7, N.2, Jul.-Dez/2003 UCPel.

GIL, Antonio Carlos. Métodos e técnicas de pesquisa social. São Paulo: Atlas, 2006.

GOMES, Pedro Gilberto. A Filosofia e a ética da comunicação na midiatização da sociedade. São Leopoldo: Unisinos, 2006.

JENKINS, Henry. Cultura da Convergência. São Paulo: Aleph, 2. ed., 2009.

LANDOWSKI, Eric. Uma semiótica do cotidiano. In: A Sociedade refletida. São Paulo: Pontes/EDuc, 1992.

MATA, Maria Cristina. De la cultura masiva a la cultura midiática. Diálogos de la comunicación, Lima: Felafacs, n.56, 1999.

MOUILLAUD, Maurice; Porto, Sérgio Dayrell (org.). O Jornal: da forma ao sentido. Brasília: Paralelo 15, 1997.

REBELO, José. O discurso do jornal: o como e o porquê. Lisboa: Editorial Notícias, 2000.

RODRIGUES, Adriano Duarte. A emergência dos campos sociais. In RODRIGUES, A. D. (et al). Reflexões sobre o mundo contemporâneo. Rio de Janeiro: Universidade Federal do Piauí. Revan, 2000.

SODRÉ, Muniz. A interação humana atravessada pela midiatização. IHU On line Revista do Instituto Humanitas, Unisinos, Número 289, Ano IX, 2009.

Disponível

em:

In:

http://www.ihuonline.unisinos.br/index.php?option=com_content\&view=article\&id=2476\&se $\underline{\text { cao }=289}$. Consulta em abril 2011.

SOSTER, Demétrio. Jornalismo midiatizado: a mídia na frente do espelho. In: FELIPPI, Ângela; SOSTER, Demétrio; PICCININ, Fabiana. (orgs.) Metamorfoses Jornalísticas: formas, processos e sistemas. Santa Cruz do Sul: Edunisc, 2007. 
VERÓN, Eliseo. Esquema para el análisis de la mediatización. In Revista Diálogos de la Comunicación, n.48, Lima: Felafacs, 1997.

Original recebido em: 21/11/2011

Aceito para publicação em: 10/07/2012

Resumo sobre o autor

Professora adjunta do

Departamento de Ciências da Comunicação da Universidade Federal de Santa Maria (UFSM). Coordenadora do curso de ComunicaçãoSocial - Jornalismo da UFSM. Jornalista (1999) e mestre (2002) pela UFSM e doutora (2007) em Ciências da Comunicação pela Unisinos. Coordena a pesquisa "A dinâmica das interações entre produção e recepção nos jornais do Rio Grande do Sul” financiada pelo programa Pesquisador Gaúcho (Fapergs 2011/2013). 